\title{
Perioperative concerns in a beta-ketothiolase-deficient child
}

\author{
Ravinder Pandey $\cdot$ P. M. Singh $\cdot$ Rakesh Garg $\cdot$ \\ V. Darlong $\cdot$ J. Punj
}

Received: 1 October 2014 / Accepted: 19 December 2014 / Published online: 7 January 2015

(C) Japanese Society of Anesthesiologists 2015

Keywords Beta-ketothiolase · Deficiency $\cdot$ Anesthesia . Child · Surgery

To the Editor:

Beta-ketothiolase deficiency is an autosomal recessive disorder of the metabolism of amino acids caused by lack of acetyl CoA-acetyl transferase-1 [1, 2].

A child aged 2.5 years, a case of beta-ketothiolase deficiency, was scheduled for surgery for laryngeal web. The medical history revealed recurrent ketosis. Presently, the child was asymptomatic. His laboratory results were within normal limits. Venous access was secured after EMLA cream application. Following overnight infusion of $5 \%$ dextrose in saline, his urinary ketones were negative. Anesthesia was induced with sevoflurane (2-8\%) in oxygen via a tracheotomy tube. Fentanyl $(1 \mu \mathrm{g} / \mathrm{kg})$ was given; the tracheostomy tube was replaced with an endotracheal tube and atracurium $(0.5 \mathrm{mg} / \mathrm{kg})$ was given. An oral pack was placed. Anesthesia was maintained with oxygen, air (50:50), and sevoflurane (MAC 1-1.5). Ringer's lactate and $5 \%$ dextrose were used as maintenance fluids with blood sugar monitoring. After surgery, the flexo-metallic tube was replaced with a tracheostomy tube, and the residual neuromuscular block was reversed. The patient was moved to the recovery room with maintenance fluid. Venous blood gas showed normal $\mathrm{pH}$ and normal anion gap.

Anesthetic management of such cases is challenging because of multisystem physiological alterations [1-3].
Presentation includes ketoacidosis, vomiting (hematemesis), bloody diarrhea, hyperpnea, hypotonus, cardiomyopathy, prolonged QT, lethargy, and coma [1-4]. Other symptoms are neutropenia, thrombocytopenia, and renal failure. Acute decompensation occurs with infection, starvation, and surgery [1-3]. A history of vomiting, rapid breathing, altered sensorium, and decreased urine output indicates impending ketosis. The anesthetic goal is to avoid factors and drugs that trigger ketosis: minimize preoperative fasting, administer glucose-based infusions, and avoid propofol and etomidate (inhibit mitochondrial enzymes) [4]. Thiopental, ketamine, volatile agents, and opioids appear safe. Adequate suction of surgical blood needs to be ensured because aspirated blood on digestion can be ketotic.

\section{References}

1. Kayani R, Botros S, Moore P. Beta-ketothiolase deficiency and pregnancy. Int J Obstet Anesth. 2013;22:260-1.

2. Arica V, Arica SG, Dag H, Onur H, Obut O, Gulbayazar S. Betaketothiolase deficiency brought with lethargy: case report. Hum Exp Toxicol. 2011;30:1724-7.

3. Sabetta G, Bachmann C, Giardinin O, Castro M, Gambarara M, Vici CD, Barlett K, Middleton B. Beta-ketothiolase deficiency with favorable evolution. J Inherit Metab Dis. 1987;10:405-6.

4. Ellinas H, Frost EAM. Mitochondrial disorders: a review of anesthetic considerations. Middle East J Anesthesiol. 2011;21:235-42.

R. Pandey · P. M. Singh · R. Garg $(\bowtie) \cdot$ V. Darlong $\cdot$ J. Punj

Department of Anesthesiology and Intensive Care, All India

Institute of Medical Sciences, Ansari Nagar, New Delhi 110029,

India

e-mail: drrgarg@hotmail.com 